\section{ORIGHTAI COMMUNICATIONS.}

\section{COMPARATIVE FREQUENCY OF DISEASE OF THE HEART AND EMPHYSEMA OF THE LUNG IN ST. GEORGE'S HOSPITAL AND THE EDINBURGH ROYAL INFIRMARY.}

\section{By W. T. GAIRDNER, M.D., Physician to the Edinburgh Royal Infirniary.}

Ir a very elaborate and excellent series of researches, founded upon the records of St. George's Hospital, and published in the British and Foreign Nedico-Chirurgical Review of the past year,* I find certain conclusions in regard to the connexion of emphysema of the lung with disease of the heart, so diametrically opposed to those published by me in the same magazine for April 1853, that I feel bound to subject them to criticism from my own point of view. Fortunately, the basis of his opinions has been so fully stated by Dr. Chambers, as to absolve him from all suspicion as to the exact and logical character of his inductions from the facts before him. In my own memoir, the details bearing on the point in question are also given; and the attentive reader of both series of researches will not fail to perceive that the difference of conclusions is founded upon a want of harmony in the statistical details, and not on any material difference in the mode of reasoning of Dr. Chambers and myself. But it will at once be conceded, that a discrepancy in facts stated as the results of observation in two large hospitals is of much more importance to the public than any theoretical differences can possibly be; inasmuch as an error in logic, if there be one, can always be detected and exposed by an intelligent reader; whereas an error of statement can in general be only rectified by the original author of it, and is therefore liable, if not corrected, to become the source of wide-spread confusion.

The subject of this communication, then, is not, strictly speaking, so much an inquiry into the opposed opinions of Dr. Chambers and myself upon a point of scientific and practical interest, as a comparative criticism of the alleged facts on which those opinions are based. But, in order that the ultimate question at issue may be fairly understood, I shall take care to state it in the course of the following remarks.

The marked tendency of hypertrophy and dilatation of the heart to be connected with emphysema of the luing is shown by the records both of St. George's IIospital and of the Royal Infirmary of Edinburgh, and is accordingly the common starting point of both commentators. It is to be observed, however, that Dr. Chambers attributes to St. George's Hospital a higher proportion of cases of cardiac enlargement, whether in emphysematous or mixed fatal cases, than is observed in the Kidinburgh Infirmary, according to my published data. In St. George's Hospital, the number of cases of hyperirophy of the heart is stated at 505 among 2,161 fatal cases sanined during ten years-a proportion of 23.4 per cen In Edinburgh, there are recorded 13 cases of enlarge .ent of the heart among 84 very carefully observed fatal vases, and 47 cases of hypertrophy in a larger and less exact series of 414 fatal cases; the proportions expressed in these numbers being respectively only 15.5 per cent. and 114 per cent. The difference between these numbers is striking enough to call for examination, independently of the correspondence or divergence of any results deduced from them.

Further, the proportion of cases of emphysema of the lung is, or appears to be, very greatly lower in the Sit. George's Hospital, than in the Edinburgh returns; at least, in that portion of the Edinburch statistics in which alone an approach to absolute aceuracy is professed. In the 84 cases in Edinburgh, above alluded to, there were 26 cases of $\mathrm{cm}$ -

- Decenuium l'athologienm, British and Foreign Med.-Chir. leview for April, July, and October, 1 : physems, or 30.9 per cent.; in the 2,161 cases at 8. . George's Hospital, there were 258 cases of emphysems in all, being not more than 11.9 per cent. Here, however, the 414 less accurately recorded cases in Edinburgh differ greatly from the minor series of 84 cases above mentioned; the proportion of emphysematous cases in the former being 9.7, or rather lower than that in St. George's Hospital.

To make these discrepancies more clear by bringing them into view at once, we find the following proportions:-

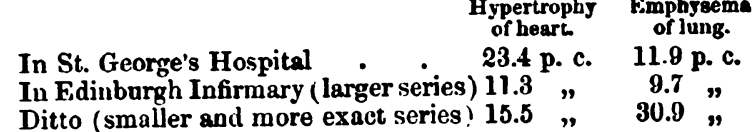

Before any conclusion can be drawn with security from these premises, at least in regard to points where they lead to different results, it is manifestly necessary to inquire whether the higher proportion of hypertrophy of the heart in London, and of emphysema of the lung in Edinburgh, be a real, or only an apparent difference between the two hospitals? This is the first question which I mean to discuss in the present communication.

1. Is hypertrophy of the heart more common in St. George's Hospital than in Edinburgh Infirmary? The numbers above given appear to answer this question very decidedly in the affirmative, inasmuch as a small series of fatal cases in the latter institution, observed and noted with the most anxious care to avoid omissions of inadrertence, presents one-third fewer cases in proportion. It might also be reasonably supposed, a priori, that, in an hospital which roceives a large proportion of the plethoric and overfed dependants of the upper classes of English society, among whom gout and perhaps also rheumatism are known to prevail in unusual proportion, disease of the heart might be more common than in the Edinburgh Infirmary, where, I believe, scarcely half a dozen cases of unequivocal gout have appeared in the course of a quarter of a century. The numerical statement, too, of the frequency of hypertrophy of the heart is made all the more striking by the consideration that, in St. George's Hospital, nearly the whole of the fatal cases form the basis of the statistics, while in Edinburgh scarcely more, sometimes not more, than one-half of the fatal cases can be examined; the majority of these being cases of peculiar interest to the physicians, $i$. e., cases of organic disease. Notwithstanding these facts, however, the question which I have raised above is by no means so simple of solution as it might appear.

On recurring to the numerical details of the 84 cases in Edinburgh, I find 13 cases of undoubted cardiac hypertrophy, or, as above stated, 15.5 per cent. But, in addition to this, there are recorded not less than 7 cases where relative hypertrophy was considered to exist, although so equally diffused as not to derange the proportion of the cavities and walls to each other, and so slight as not to constitute, in my opinion at the time, a case for admission into a numerical series. The large proportion of these doubtful cases to the whole of those where hypertrophy was recorded shows (what every accurate observer of post mortem phenomena knows, but what might easily escape a superficial reader) that the determination of the absolute number of cases of cardiac hypertrophy in a given series is necessarily to some extent an arbitrary calculation. The size of the heart bears a proportion to the size, strength, and fulness of blood in the individual case; and the extent to which this proportion may vary, within the limits of health, has never yet been very precisely determined. I have never, accordingly, recorded a heart as enlarged, merely because it exceeded the usual averages; but have constantly sought for corroborative evidence to estimate the existence of truly marbid hypertrophy. Had I taken even the maximum estimate* of the average weight of the heart, and reckoned all above this as hypertrophy, the pro-

- The largest estimate, being that of Dr. John Reid, gives as the arerage, a or. for females, nud $11 \mathrm{oz}$. for mnles. But in a number of adult males dying while in full health, the arerage weight was found to be abore $12 \mathrm{oz}$. 
prtion of cases in the abore list would, I believe, have been hereased abore its present amount, even including all the aces recorded as doubtful. But, by calculating only the 7 clight doubtful cases in addition to the 13 above mentioned, ve arrive at a proportion somewhat higher than that of St. teorge's Hospital, viz., 23.8 per cent.

I have no means of knowing the data on which the anacomical eatimate of hypertrophy has rested in the cases at Bt. George's Hospital; it is even probable, or nearly certain, that, in a series of cases extending over ten years, and recerded by many different hands, the grounds of this estimate must hare occasionally varied to a considerable extent. Under these circumstances, it would undoubtedly be premature to consider the question as to the relative frequency of cardiac hypertrophy in the London and in the Idinburgh institution, numerically decided; though circumstances, to which I have already referred, point to the trong probability that this affection is really more frequent in the former institution; and the numerical anaIysis, if it does not strongly confirm, is at least not unfavourable to this viev.

That cardiac disease is, on the whole, more prevalent in 8t. George's Hospital than in Edinburgh Infirmary, is further rendered probable by a very careful analysis which I have made of the cases of valvular and endocardial thickening and deposit. In St. George's Hospital, these are said to amount to 17 per cent. of the entire cases examined. In Rdinburgh, where, as I have said above, the examinations are more select, and where, consequently, cases of known or wupposed organic disease may be expected to preponderate, the propertion of ralvular thickenings and deformities is very little, if at all, different in the 84 carefully recorded cases; in the larger series, it is very much lower. But, as it can scarcely be supposed that a variety of observers continued to employ during ten years, and throughout 2,161 examinations, the minute care which I devoted to these 84 cases (for I believe no thickening or opacity, however slight, to have been overlooked), it follows, as every way probible, that the numbers in St. George's Hospital were in reality higher than those in the Edinburgh Infirmary. To what extent this was the case, it is of course impossible to say.

I believe, then, that the proportion of fatal heart-diseases may be safely assumed to be greater in the London than in the Edinburgh institution; for this conclusion is not only probable a priori, but is consistent with strong probabilities derived from numerical returns.

2. Is emphysema of the lung more common in Edinburgh Infirmary than in St. George's Hospilal? The immense interval between 30.9 per cent. in the one institution, and 11.9 per cont. in the other, will appear to many to be capable of no other explanation; but such persons cannot be awrere, by practical experience, of the difficulty of collecting the data for such statistics; and, however it may shock the faith of those who have been accustomed to trust in them without inquiry, I am induced, by my owu knowledge of the subject, to regard the difference of numerical data as merely expressive of the different degree of attention given by the recorders to the subject in question. Among the almost infinitely numerous facts which may be recorded in the dissecting theatre of the hospital, emphysema of the lung is one of those which, by the very frequency of its elighter degrees, is sure to escape particular attention in the majority of instances, unless the determination be formed beforehand to look for it, and record it if present. It is simply to the circumstance of my having done this in each of the 84 cases on which the above numerical result rests, that I ascribe the apparent high proportion of inetances in which emphysema of the lung is recorded; inasmuch as I fully believe that, in a large series such as that of St. George's Hospital (or such as that in which I myself found 9.7 per cent. of emphysems), it is quite unreasonable to expect a similar amount of care to avoid omission. In fuct, a considerable proportion of the cases of emphysems neted by me were individually of exceedingly small importanes in relation to the history of the afection, and could only be of value by presenting a complete series for the investigation of such pathological inquiries as those in which Dr. Chambers and myselt have been engaged. Further, a large number of emphysematous cases is apt to escape being recorded, because the emphysema is manifestly only a part of the phenomena of some other more important condition, such as retrograde tubercle; but, in all of these instances, the emphysema, as well as the more prominent affection, is noted in the small series of which I have given the numerical results.

3. What is the pathological relation between emphysema of the lung and hypertrophy of the heart? I have already romarked, that the London and Edinburgh statistics agree in demonstrating a close connexion between these two affections; but the doctrines, as to the mode of that connexion, which have been deduced by Dr. Chambers on the one hand, and by myself on the other, from the facts before us, are very different. The deductions of Dr. Chambers on this point are as follows:-

"1. Emphysema has a very marked tendency to be connected with all forms of disease in the heart, or in its valves and ressels. 2. The tendency is most marked in cases where the valves are diseased, as well as the muscular walls. 3. Valvular disease alone, and aortic disease alone, have some tendency to be connected with emphysema, and the latter more than the former. 4. Where cardiac disease is associated with emphysema, it is most likely that the former is the primary lesion." *

In the points denoted by italics, the Edinburgh statistics lead to conclusions opposed to those of Dr. Chambers; and, as I have elsewhere discussed at length the theory as to the connexion of emphysema with disease of the heart, which appeared to me most accordant with these and other facts bearing on this subject, I may be excused for stating my reasons for believing that a fallacy lurks under the numbers indicated in the returns of St. George's Hospital, and that this fallacy is to some extent avoided in the Edinburgh roturns. It has been shown above, that, in a large proportion of the cases indicated in the returns of St. George's Hospital as non-emphysematous, emphysema, to a greater or less extent, was in all probability present. It is in the highest degree unlikely, if emphysema and hypertrophy of the heart be, as both returns show, closely related to each other, that, in the hospital presenting the largest proportion of cases of the latter affection, the latter should be comparatively rare; yet this inconsistency would necessarily arise from the returns of St. George's Hospital, if these are to be accepted as representing the exact truth in regard to emphysema. I have given above what appear to mo good reasons for believing that, while the statement of cases of hypertrophy of the heart approaches the truth, that of the emphysematous cases in St. George's Hospital is vitiated by a large number of errors of omission, being those chiefly in which emphysema was secondary to other more striking and more evidently primary diseases of the lung. If, for instance, the cases of pulmonary emphysema depending on obsolete tubercle, or on what has probably been termed chronic preumonia (pulmonary indimation and atrophy), have been, to any considerable extent, omitted from the register of emphysematous cases, a very large gap indeed must have been thus created-one quite sufficient, if $\mathbf{m J}$ researches on this subject are correct, to explain the disappearance of the large number of cases absent in the London, and present in the Edinburgh , returus. Indeed, it appears to me sufficiently evident that the St. George's Hospital returns contain only those cases of emphysema in which it constituted the principal pulmonary affection, and had been in all probability one of the chief causes of death.

If this be so, there can be no difficulty in explaining why the St. George's Hospital returns present a view of the relation of emphysems to disease of the heart, 80 different from that which I have maintained. An immense 
proportion of cases of emphysems of the lung does, in fact (as every one who has paid the slightest attention to the subject knows), take origin in retrograde pulmonary tubercle. Almost every recent pathological anatomist has given testimony to this fact, although there has been considerable difference of opinion as to the rationale of the connexion. By an analysis of a considerable number of cases of dilatation of the heart, without valvular disease, I have shown that this affection, also, is an exceedingly frequent accompaniment of retrograde and obsolete tubercle, as well as of other atrophic diseases of the lung; and that simple hypertrophy and dilatation of the heart is related to disease of the lung chiefly through that atrophy of the pulmonary tissue, which is the cause both of emphysema and of dilatation of the heart, and the source of their relation to each other, and of their very frequent concurrence in the same subject. The careful researches I have made on this subject, therefore, corroborate to a certain extent the common opinion, that emphysema of the lung is more apt to be followed by cardiac hypertrophy than to take origin from it; while the returns of St. George's Hospital appear to sanction the opposite opinion. Again, the result of my investigation is in accordance with the statements of most other authors, in respect to the kind of cardiac disease which follows most frequently on emphysema; viz., hypertrophy without valvular disease chiefly of the right side. The returns of St. George's Hospital, on the contrary, assign to emphrsema a higher ratio of connexion with valvular disease than with simple hypertrophy. The reason, however, of both these discrepancies is ovident, if we bear in mind what has been stated above, to the effect that the London lists of emphysematous cases must be read with allowance for the omission of a great proportion of them, including most of those in which the true genesis of emphysema, and its connexion with non-valvular disease of heart, are most conclusively shown.

I do not hesitate, then, to express my opinion, that Dr. Chambers has (not by any fault of his own, but by the inaccuracy of his materials) been led into error as regards the relation of emphysemu to disease of the heart. The immense accumulation of cases of which he has made, for the most part, such admirable use, presents an erroneous bias throughout which it is not difficult to explain, and of which any one may at once convince himself by observing forty or fifty miscellaneous dissections in an hospital, with special reference to this point. He will then see that pulmonary emphysema is an almost invariable concomitant of retrograde and obsolete tubercle; and that in a large proportion of the cases in which these two affections concur to any marked extent, hypertrophy and dilatation of the heart, chiefly of the right side, and without valvular disease, also occur. Bearing in mind the fact, that tubercle, under other eircumstances, is very rarely indeed connected with hypertrophy of the heart, he will at once be led to the conclusion, that pulmonary emphysema and cardiac hypertrophy have a common point of origin in tubercular cases, and that the determining cause of both affections is connected, in some way or other, with the retrogression of the tubercles. Having seertained these facts, he will scarcely have any difficulty in satisfying himself that in tubercular cases the cardiac affection is never primary, being often absent when emphysema is present to a notable degree, and very often slight, when the latter is considerable in amount. For the detailed arguments in favour of the view that cardiac hypertrophy and pulmonary emphysema are collateral sequelce of atrophic affections of the lung, I must refer to the paper already mentioned.

Tubercular cases form the instantice cracis for determining the mode of origin and connexion of the two pathological conditions to which the above remarks refer; because in them it cannot be disputed that both the onc and the other are secondary consequences of the original pulmonary affection. But the principle determined by an analysis of such cases may be safely applied to others in which cardiac hypertrophy and emphysema concur; and I believe there will be found fer exceptions to the above law of their mutual connexion. I am far, howerer, from wishing to deny that primary cardiac dicoses may, under cortain circumstances, tend to generate pulmonary emphysem as a secondary condition. This is even probable a priori, from the consideration of the frequency of bronchitis in candiac valvular affections. But any tendency which thus arises to emphysema is in the majority of cases counterbalanced by the occurrence of dropsy of the serous cavities; a condition, of all others, most opposed to the production of this pulmonary lesion. So that, upon the whole, I believe my own statistical conclusion (although founded on too narror a basis for induction) to be not far from the truth; viz., that valvular disease of the heart, per se, presents no particular relation to pulmonary emphysema, nor does it, on the whole, tend greatly to exclude this affection. It should be kept in view also, that the conditions in which emphysems of the lung has its origin tend also greatly to aggravate disease of the heart in all its forms, and may often give to a latent disorder of the valvular apparatus, that fatal impulse which superadds to it dilatation of the cavities, hypertrophy of the walls, and their well known sequelæ. So that, eren in valvular affections of the heart, the coexistence of emphysema of the lung is, in many cases, neither to be looked upon as a result of the major affection, nor as an independent phenomenon: but as one of the circumstances tending most strongly to precipitate the cardiac disease to a fatal termination.

I conclude by giving from the British and Foreign Medico-Chirurgical Review, the following proportions, which may be of use to others in pursuing allied inquiries, and which I believe to be as nearly accurate as the nature of the investigation and the small number of cases will allow.

In a series of 84 mixed cases, most carefully observed and recorded with reference to these points.

Hypertrophy of the heart occurred 13 times* $=15.5$ per cent. Ditto, with valvular diseaset 6 times $=7 \cdot 1$ ditto Emphysema of the lung 26 times $=50.9$ ditto Among these 26 cases of emphysema,

Hypertrophy of the heart occurred 6 times $=23.1$ ditto Ditto, with valvular disease, trice.

Edinburgh, January, 1854.

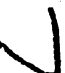

\section{CASE OF CANCER OF THE KIDNEY.}

By AUGUSTUS EVES, M.D., F.R.C.S., Surgeon to the Cheltenham General Hospital.

THE subject of this case was a gentleman, aged 38. As I saw him for the first time about a fortnight before his death, I have endearoured to procure the previous history of his illness from his mother; of which the following is a brief abstract.

Previous History. Mr. - was of full habit, and apparently healthy, until the summer of 1852 , when a gradual but progressive emaciation became apparent. In December of the same year, he had severe pain in the left lumbar region and left side of abdomen, accompanied with considerable hæmaturia. This pain recurred violently in paroxysms during the following two or three months, abating in the intervals, but not completely disappearing; the hæmaturia also being a most frequent concomitant. This last mentioned symptom occurred at intervals throughout the disease; and in July 1853, the surgeon in attendance was obliged to pass a catheter, on account of retention of urine, from the neek of the bladder being filled with coagulated blood. This coagulation of blood in the bladder, was, at different times throughout the disease, a cause of great irritation and difficulty, as regarded emptying the bladder, From the first attack of pain, there was frequent romiting, with almost constant nausea; the appetite for food gradually becamo impaired; and at last he coudd scarcely take any nourish-

- Fxciusive of doubtrul cases, as mentioned above.

+ By valvular diserse, it is not meant (as in the St. George's Hospital returns) to include every instance of endocnrdial thickening or deponit, buc retur those evidently causing functional disturbance. The cases of eadocardial disease in the wider seuse amount to more than 17 per cent. 